\title{
¿Por qué un lado del cerebro ejerce control motor sobre el lado opuesto del cuerpo? Teoría del ahorro energético.
}

Why does one side of the brain exert motor control over the opposite side of the body? Theory of energy saving.

\section{Euro Murzi ${ }^{1}$, Trino Baptista $^{1}$, Noris Menesini ${ }^{2}$}

\section{Señores Editores:}

La mayoría de los animales poseen sus cuerpos y sistemas nerviosos divididos semi-simetricamente en dos mitades, izquierdo y derecho, tal vez porque para su sobrevivencia, sus cerebros dividieron arbitrariamente el mundo de manera semejante. Para nadie es extraño que ambas mitades nerviosas deban comunicasen ente si mediante múltiples decusaciones para poder funcionar coordinadamente como un todo. Lo que si extraña, es que un lado ejerza control somático motor y sensitivo sobre la mitad opuesta, lo que ha llevado a algunos autores a afirmar que esta característica debe ser "muy importante pero inexplicable" $(1,2)$; estos no se refieren a la decusacion per se (por su existencia obvia) sino al control funcional contralateral que ejercen.

Sin embargo, si sabemos que cada hemisferio cerebral "ve" exclusivamente el lado opuesto o contralateral (debido a la decusacion quiasmática), y que el procesamiento motor-sensitivo se realiza en conjunto debido a las áreas de asociación cortical, entonces es comprensible que ese hemisferio, y no el otro, sea el que ejerza el control motor y sensitivo directo (ahorro energético) de lo que él "ve" (figura 1). Creemos que esta explicación que expusimos, poco sofisticada comparada con otras (3), podría explicar lo "inexplicable". Revisando la literatura conseguimos un hecho interesante que no podemos pasarlo

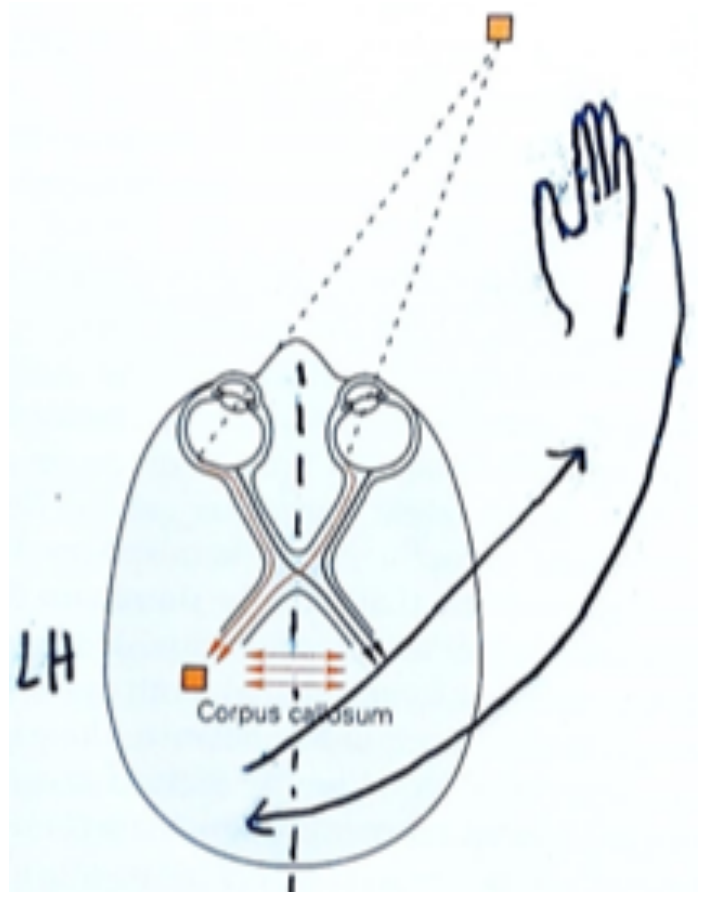

Figura 1. Los fotones reflejados por el objeto cuadrado ubicado en el campo visual derecho inactivan la retina temporal izquierda y la nasal derecha, creando una imagen exclusivamente en el hemisferio izquierdo (LH), aunque esta imagen, secundariamente, alcanza el hemisferio derecho a través del cuerpo calloso. Por lo que no es "inexplicable", por ahorro energético, que el LH controle la mano derecha que está más cercana (flecha negra corta), aunque el hemisferio derecho también lo puede hacer con la mano izquierda. La sensibilidad está representada por la flecha negra larga.

Departamento de Fisiología, Facultad de Medicina, Universidad de los Andes. Mérida, Venezuela

2 Servicio Nacional de Medicina y Ciencias Forenses. Mérida, Venezuela 
desapercibido aquí. La corteza parietal derecha parece mediar la atención o focus hacia la mitad izquierda cuerpo, pero también incluye la derecha, mientras que la corteza parietal izquierda solo media la atención hacia la derecha. Esta observación ha sido confirmada por imagenología de la actividad del lóbulo parietal durante tareas de atención específicas realizadas en sujetos normales. La cual muestra que el flujo sanguíneo aumenta en ambas cortezas parietales cuando se les pide que realicen tareas en el campo visual derecho, pero cuando el desafío es en el campo visual izquierdo, solo se activa la corteza parietal derecha (2). Esta sobre-atención (o hiperfocus) de ambos hemisferios sobre el campo visual derecho, podría explicar la predominancia del uso de la mano derecha en el $90 \%$ de los humanos.

Aunque algunos investigadores han tratado de encontrar una correspondencia entre la localización hemisférica izquierda del lenguaje con el control motor de la mano derecha, los zurdos incumplen esa relación; sin embargo, en estos se nota una mayor preponderancia derecha al lenguaje (2). Estas asimetrías hemisféricas parecen tener ventajas evolutivas. Por ejemplo, un pájaro necesita un focus limitado sobre un grano de alimento para distinguirlo de los trozos de arena o piedrecillas adyacentes, pero al mismo tiempo, necesita de un focus abierto, más amplio, para protegerse contra un posible depredador en la cercanía (poder comer sin que lo coman) (4).

En conclusión, podemos afirmar junto con Purves et al.,(2), que, con toda probabilidad, la laterización de la visión, de la mano, del lenguaje, son ejemplos de las ventajas de tener algunas funciones especializadas en un lado del cerebro y otras funciones en el otro lado, permitiendo así, hacer uso máximo de los circuitos neuronales disponibles en un cerebro que es de tamaño limitado.

\section{Correspondencia.}

Trino Baptista

Correo electrónico:trinbap@yahoo.com

\section{REFERENCIAS BIBLIOGRÁFICAS}

1. Kandel E, Schwartz R, Jessell J. H. Principles of Neural Science. New York: McGraw-Hill; 2000. p. 324.

2. Purves D, Augustine GJ, Fitzpatrick D, Lawrence C K, LaMantia AS, McNamara JO, et al. Neuroscience. Sunderland, USA: Sinauer Assoc; 2001. p. 597.

3. Mora C, Velásquez C, Martino J. The neural pathway midline crossing theory: a historical analysis of Santiago Rámon y Cajal's contribution on cerebral localization and on contralateral forebrain organization. Neurosurg Focus. 2019;47(3):E10. doi: 10.3171/2019.6.FOCUS19341

4. Rogers LJ. Evolution of hemispheric specialization: advantages and disadvantages. Brain Lang. 2000; 73:236-253.

Recibido: 26/10/2020

Aceptado: 27/04/2021 